\title{
Management of a Ethmoido-Orbital Mucocele with an Acute Installation: a Case Report
}

Chafiki Zakaria*, Widadi O, Merzouki B, Halily S, Rouadi S, Abada R, Roubal M and Mahtar M

Department of ENT, Ibn Rochd University Hospital, Morocco

Submission: February 19, 2017; Published: March 06, 2017

*Corresponding author: Chafiki Zakaria, Hopital 20 Aout, ENT Service, CHU Ibn Rushd, Casablanca, Morocco, Email: zakaria.chafiki@gmail.com

\begin{abstract}
The interest of this article is to show that a quick and adequate medico-surgical management leads to good results in a sinusal pathology, which is sometimes clinically and radiologically impressive, and its particularity resided in the quick installation of exophthalmia, revealing the diagnosis , the excellent postoperative results and the particular location of this mucocele.

Keywords: Mucocel; Paranasal sinuses; Exophtalmia
\end{abstract}

\section{Introduction}

The mucoceles are expansive pseudo-cystic formations developed in the sinuses of the face, contain glandular secretions, leading to an obstruction of the drainage of these sinuses by retention. Their envelope is formed by a modified sinus mucosa. Their location predominate in the frontal sinus, followed by the ethmoid and more rarely in the sphenoidal and maxillary sinuses. The mucoceles can be a source of serious complications, which is why their diagnosis must be quick and their management without delay. Results

Was admitted to ENT emergencies a 24-year-old patient, with no specific pathological history, suffering from serious acute exophtalmos (less than 7 days), visual fog, decreased visual acuity, intense headache, resistant to analgesic treatment. The clinical examination found a left exophthalmos grade III, conjunctivitis and keratitis of the left eye, paralysis of the oculomotor muscles. CT scan of the face recovered an intra sinusoidal formation involving the ethmoidal cells and the left frontal sinus. The MRI described the appearance of a frontoethmoid mucocele lysing the inner wall of the left orbit and an extraorbitalintraorbital collection responsible for a left grade III exophthalmos (Figure 1).

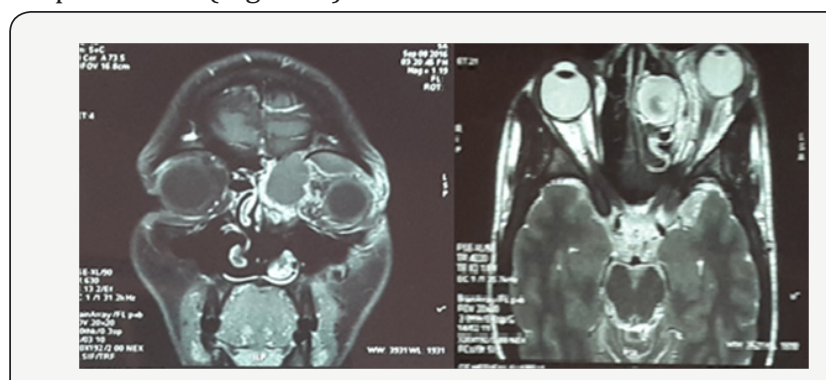

Figure 1: MRI injected in frontal and axial section showing the mucocele.

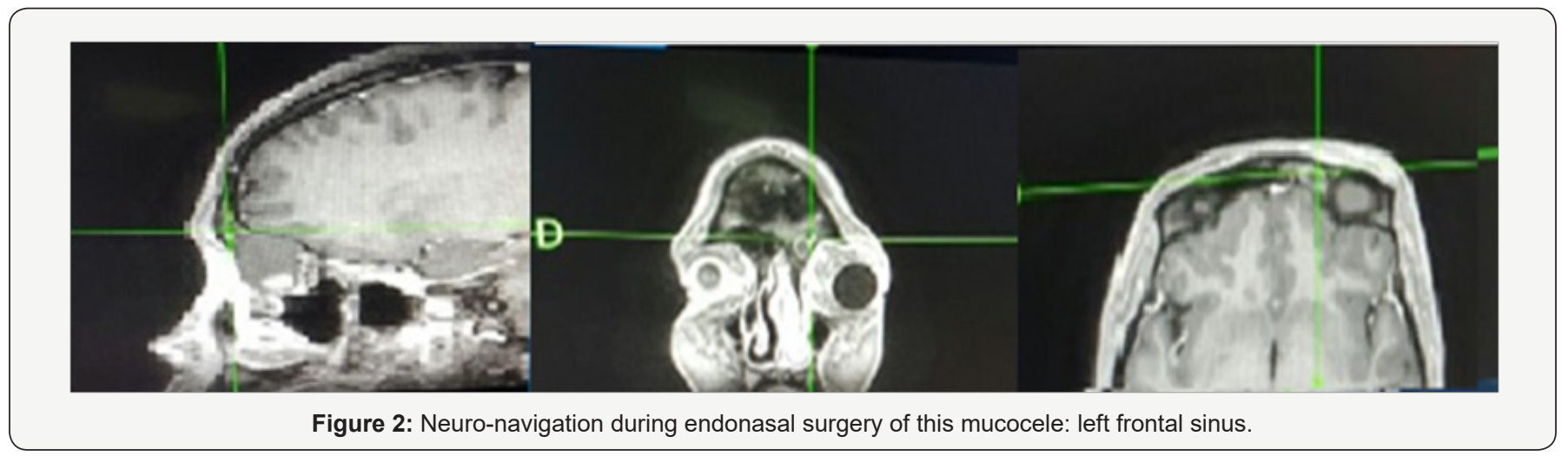

Glob J Otolaryngol 4(4): GJO.MS.ID.555642 (2017) 


\section{Global Journal of Otolaryngology}

Treatmenthad begun with artificial tears, left blepharography to protect the left cornea, methylprednisolone boluses, followed by combined surgery involving an endonasal approach and an external one. The endonasal approach was made using neuronavigation system (Figure 2), consisting in a metatotomy, an earlier ethmoidectomy, DRAFT II leading to the discovery and the recess of the cavity of the mucocele. As said earlier, the access to the mucocele was also by the external approach, by left upper ortbital access, resulting to communication of the two cavities and causing the collapse of the globe. The lacrimal sac was not affected. The postoperative period was characterized by a total regression of the exophthalmos (Figure 3), a marked improvement of the visual acuity, from $2 / 10$ to $7 / 10$ and the decrease in headache. The follow-up after one year was without abnormalities.

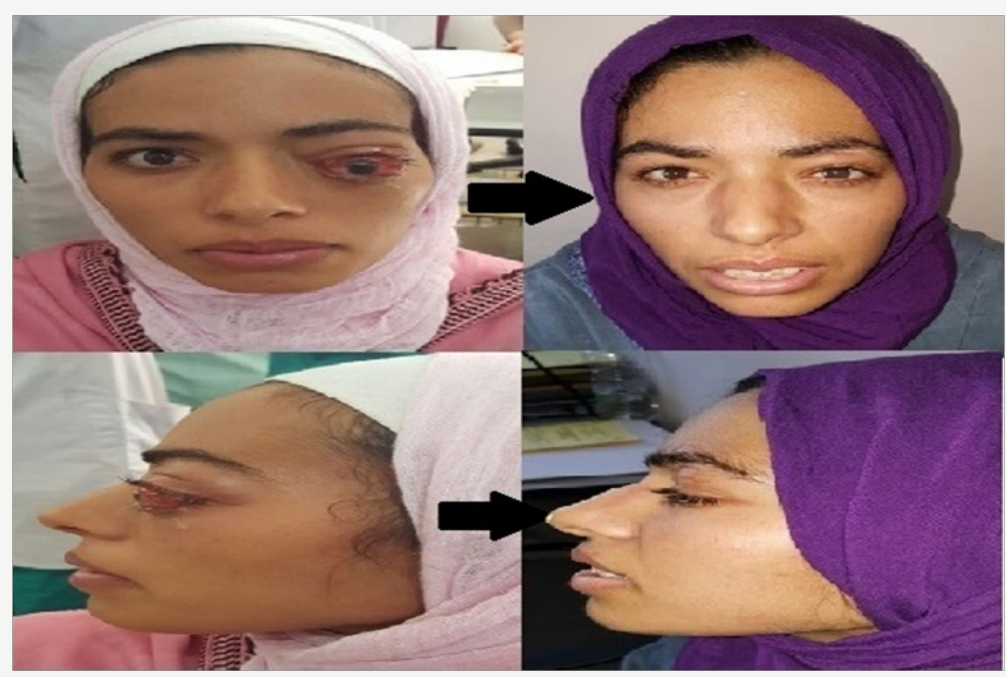

Figure 3: Exophtalmos, before (at the left) and after (at the right) the surgery.

\section{Discussion}

A mucocele is a benign pseudokytic formation developing in a nasosinus cavity. Its evolution is long, taking a pseudotumoral aspect. Its wall is formed by a modified sinus mucosa and the interior is formed of glandular secretions. Its formation related to a cystic retention, by obstruction of the normal drainage of the sinuses [1].

The frontal sinus $(60-89 \%)$ is most often followed by the ethmoidal sinus $(8-30 \%)$ and the maxillary sinus $(<5 \%)$. The frontal and ethmoidal mucoceles are characterized by a lack of specificity of their Clinical signs and slow development, which may delay or distort the diagnosis. The clinical manifestations are mainly algic, and of ophtamological order [2,3]. The specificity of our case was the speed of symptom establishment in the patient, less than a week, with the development of a very important exophthalmos in this record time.

This exophthalmia is linked, in the literature, to the expansive nature of the mucocele, resulting in a displacement of the orbital contents, and often the local bone lysis. Several studies in the literature show that the endonasal route alone can be used in the majority of cases [4]. Extensive FOE mucoceles can be successfully and safely treated by endoscopic and non-endoscopic methods. The choice of surgical approach mainly depends on the anatomy of the frontal recess. Traditionally, non-endoscopic treatment of FOE mucoceles has involved trephination procedures or osteoplastic flap with mucosal extirpation and fat obliteration [5]. Recently, Lai et al. [6] suggest the transcaruncular approach may be best for the surgical correction of FOE mucoceles because of its potential for decreased risk of damaging orbital structures [5]. Endoscopic techniques including marsupialization and modified endoscopic Lothrop procedure (MELP) have been used successfully to reduce both complicated frontal mucoceles and mucoceles of other paranasal sinuses [7].

\section{Conclusion}

Extensive fronto-ethmoidalmucoceles can be successfully and safely treated by endoscopic and non-endoscopic methods. The choice of surgical approach mainly depends on the location of the mucocele, the anatomy of the frontal recess, and other anatomical consideration for the better approach. The presented case showed good postoperative results, with a combined surgical approach.

\section{References}

1. Busaba NY, Salman SD (2003) Ethmoid mucocele as a late complication of endoscopic ethmoidectomy. Otolaryngol Head Neck Surg 128(4): 517-522.

2. Lin CJ, Kao CH, Kang BH, Wang HW (2002) Frontal sinus mucocele presenting as oculomotor nerve palsy. Otolaryngol Head Neck Surg 126(5): 588-590.

3. Gavioli C, Grasso DL, Carinci F, Amoroso C, Pastore A (2002) Mucoceles of the frontal sinus. Clinical and therapeutical considerations. Minerva Stomatol 51(9): 385-390. 
4. Herndon M, McMains KC, Kountakis SE (2007) Presentation and management of extensive fronto-orbital-ethmoid mucoceles. Am J Otolaryngol 28(3): 145-147.

5. Han JK, Higgins TS (2010) Management of orbital complications in endoscopic sinus surgery. Curr Opin Otolaryngol Head Neck Surg 18(1): 32-36.
6. Lai PC, Liao SL, Jou JR, PK Hou (2004) Transcaruncular approach for the management of frontoethmoidmucoceles. Br J Ophthalmol 88(5): 699-703.

7. Jwu Jin Khong, Raman Malhotra, Dinesh Selva, Peter John Wormald (2004) Efficacy of endoscopic sinus surgery for paranasal sinus mucocele including modified endoscopic Lothrop procedure for frontal sinus mucocele. J LaryngolOtol 118(5): 352-356.

\section{Your next submission with Juniper Publishers will reach you the below assets}

- Quality Editorial service

- Swift Peer Review

- Reprints availability

- E-prints Service

- Manuscript Podcast for convenient understanding

- Global attainment for your research

- Manuscript accessibility in different formats ( Pdf, E-pub, Full Text, Audio)

- Unceasing customer service

Track the below URL for one-step submission https://juniperpublishers.com/online-submission.php 